Intervencion (ISSN-2448-5934), julio-diciembre 2018, año 9, núm. 18: 80-86. DOI: 10.30763/Intervencion.2018.17.202

\title{
Kurt Stavenhagen, coleccionista de arte prehispánico
}

\author{
Kurt Stavenhagen, Collector of Pre-Hispanic Art \\ Christopher Vargas Reyes \\ Centro de Investigación y Estudios Superiores en Antropología Social (CIESAS-Sureste) México \\ christopher_vargas_r@encrym.edu.mx
}

\section{Resumen}

Esta SEMBLANZA parte de la figura del coleccionista alemán Kurt Stavenhagen y su mirada estética al patrimonio, para cruzarla con la perspectiva nacionalista posrevolucionaria manifiesta en el Museo Nacional, en el Museo Nacional de Antropología (MNA, México) y en exposiciones internacionales, con el fin de observar cómo ambas visiones o narrativas contribuyeron con la legitimación y el posicionamiento del arte prehispánico, a la par que colaboraron con la construcción de una nueva identidad nacional. En el escrito se muestran datos biográficos del coleccionista, así como las miradas nacionalista posrevolucionaria y la privada en relación con el patrimonio arqueológico, junto con las temáticas creadas por el alemán para entender su acervo.

\section{Palabras clave}

Kurt Stavenhagen; colección; arte prehispánico; narrativas; nacionalismo posrevolucionario; México

\section{Abstract}

This OVERVIEW is based on the German collector Kurt Stavenhagen and his aesthetic view of heritage. We cross-reference it with the post-revolutionary nationalist perspective manifested in the National Museum, the National Museum of Anthropology in Mexico (MNA, for its acronym in Spanish), and other international exhibitions in order to observe how both visions or narratives contributed to the legitimization and positioning of pre-Hispanic art, while collaborating with the construction of a new national identity. The document shows biographical data on the collector, as well as the post-revolutionary nationalist and private perspectives on the archaeological heritage, and the themes created by Stavenhagen to understand his collection.

\section{Keywords}

Kurt Stavenhagen; collection; pre-Hispanic art; narratives; post-revolutionary nationalism; Mexico 


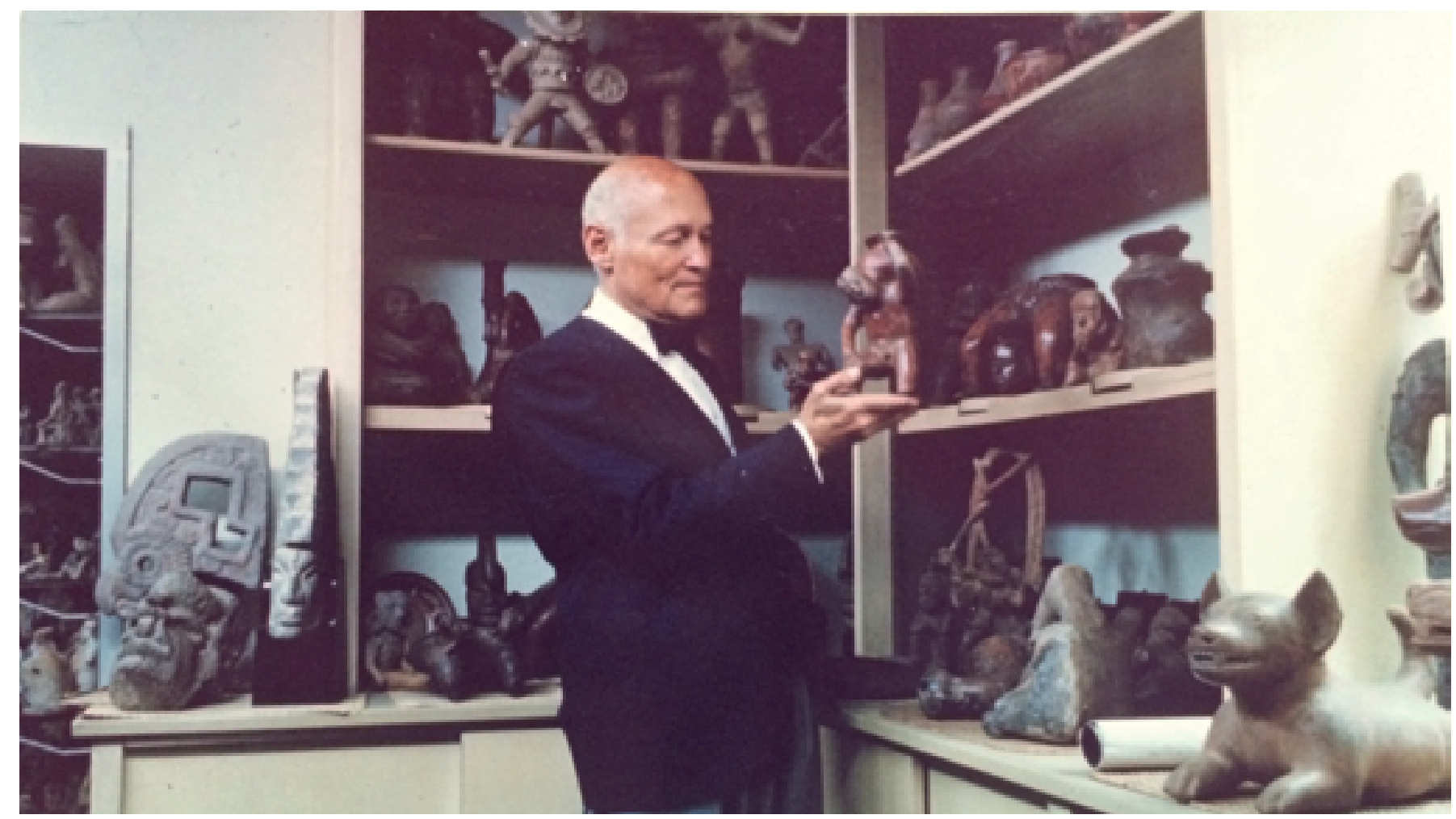

FIGURA 1. Kurt Erwin Stavenhagen en su casa junto a la colección (Fotografía: familia Stavenhagen, ca. 1959-1962; cortesía: Archivo privado de la familia Stavenhagen).

\section{Introducción}

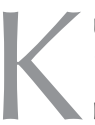
urt Erwin Stavenhagen (18991984), de origen alemán, comerciante de joyas, migró a México en 1940 debido a las persecuciones nazis antisemitas que amenazaban su vida. Si bien entró en el país como negociante, "debiendo invertir en industria agrícola en Puebla o Morelos un capital de 23900 pesos" (Segob 1940: 1-2), se dedicó al negocio de las joyas. En su nueva patria coleccionó más de 3000 piezas de arte prehispánico de mediano y pequeño formatos provenientes de Nayarit, Colima, Jalisco, Puebla, Veracruz, Guerrero, Campeche y la Ciudad de México (Figura 1).

En su época se formaron varias colecciones privadas similares, influidas por la mirada o narrativa nacionalista posrevolucionaria que promovía el redescubrimiento de los valores estéticos del México antiguo. Estos acervos motivaron la fundación de museos como el de Arte Prehispánico de México Rufino Tamayo, el de Arte Prehispánico Carlos Pellicer, el Diego Rivera Anahuacalli y el Museo Colección Stavenhagen (MCS) en el Centro Cultural Universitario Tlatelolco (CCUT).

El propósito de esta SEMBLANZA es analizar el cruce entre la mirada estética nacionalista posrevolucionaria y la mirada privada sobre el arte prehispánico a través de la figura de Kurt Stavenhagen, para comprender cómo ambas promovieron la revaloración de la estética mesoamericana y contribuyeron con su legitimación como arte en un contexto que las consideraba "obras primitivas". Para lograrlo, considero fundamentales los aportes teóricos-conceptuales de Walter Benjamin en "El coleccionista" (Benjamin 2013) y Jean Baudrillard con El sistema de los objetos (Baudrillard 1969): ambos permiten comprender la pieza de colección como un objeto que queda liberado de sus funciones originales para formar parte de un nuevo mundo confeccionado por su propietario y que documenta una imagen autobiográfica del coleccionista. También los trabajos de Luis Gerardo Morales, Orígenes de la museología mexicana
(Morales 1994), y de Ignacio Bernal, Historia de la arqueología en México (Bernal 1992), aportan información sobre la práctica del coleccionismo privado e institucional, así como de los criterios de selección empleados para construir colecciones.

Respecto de la metodología y las fuentes empleadas, esta investigación se define por ser de tipo documental, donde las de carácter oral (entrevistas a familiares) y artículos de prensa fueron fundamentales para descubrir aspectos biográficos de Stavenhagen difíciles de conocer debido a la escasa información sistematizada y publicada.

\section{La mirada estética-nacionalista}

Según Rodolfo Stavenhagen (Stavenhagen 2011), su padre comenzó a formar la colección de arte prehispánico en 1943 o 1944, por lo que la narrativa que confeccionó para explicar su acervo tiene como antecedente e influencia la museopatria, término conceptualizado por Morales para analizar la entrada del patriotismo y 


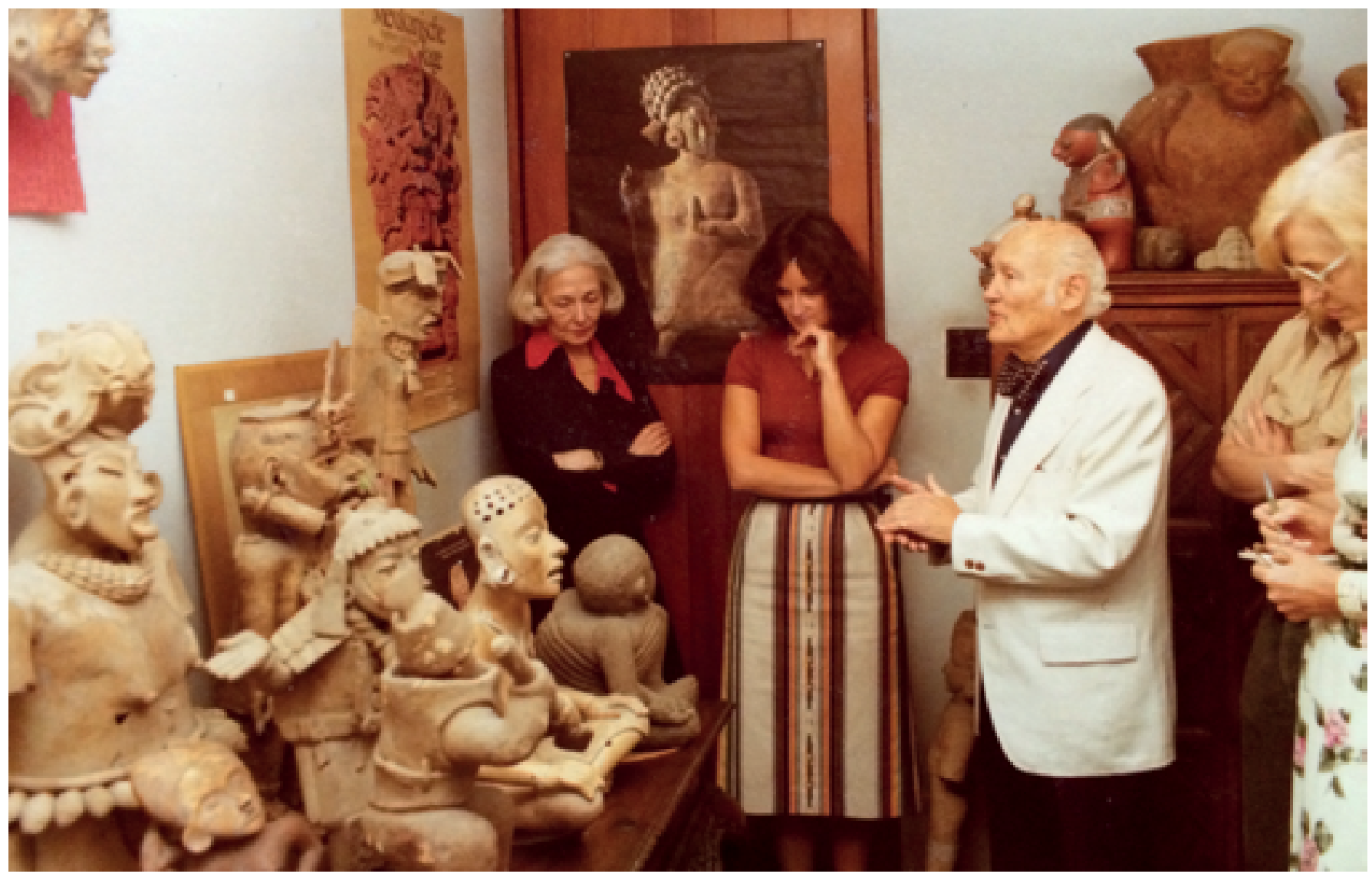

FIGURA 2. Kurt Stavenhagen haciendo una visita guiada por la pequeña galería que construyó en su casa (Fotografía: familia Stavenhagen, ca. 1972 1977; cortesía: Archivo privado de la familia Stavenhagen).

el nacionalismo en la configuración de discursos, colecciones y prácticas en los museos (Morales 1994). Estas narrativas nacionalistas incorporaron creencias individuales, colectivas, científicas y míticas de lo que se consideraba "lo mexicano", lo autóctono, lo que caracterizaba y sustentaba la identidad de la nación (Morales 1994); por ello enfatizaban el valor estético de las obras prehispánicas en el mundo del arte universal, en contraposición con la mirada colonialista, que las consideraba primitivas, término heredero de la calificación que hacían de sus creadores (Ocampo 2011), para, concluir y divulgar que el arte mexicano tenía más de 2000 años de antigüedad y poseía valores estéticos propios. En este sentido, la narrativa posrevolucionaria buscó contribuir con la creación de una identidad nacional original y el patrimonio arqueológico mesoamericano sirvió para lograrlo.
Con la profundización académica del nacionalismo cultural posrevolucionario se promovieron nuevas lecturas estéticas del pasado prehispánico, como las trabajadas por Eulalia Guzmán (Guzmán 1933), Edmundo O'Gorman (O'Gorman 2002), Justino Fernández (Fernández 1972) y Paul Westheim (Westheim 1955), autores que nutrieron la percepción con la que Stavenhagen entendió, ordenó y explicó el mundo prehispánico.

\section{La mirada privada}

Para estudiar la narrativa confeccionada por el coleccionista, son relevantes tres elementos teóricos-conceptuales. El primero es el tratado en los párrafos anteriores respecto del nacionalismo cultural en turno como eje interpretativo de piezas prehispánicas; el segundo es observar el acervo en los términos que sugiere Bau- drillard (Baudrillard 1969), donde los objetos de colección se caracterizan por quedar liberados de su función original para convertirse en un espejo que refleja la imagen deseada de su dueño, y el tercero corresponde con el método empleado por los coleccionistas para hacer presentes sus objetos, los cuales se plantan "en nuestro espacio (y no nosotros en el suyo)" (Benjamin 2013: 342). La casa donde vivió Stavenhagen con su familia está ubicada en la colonia San Ángel Inn, en la Ciudad de México. Allí construyó una pequeña galería para resguardar, estudiar y exhibir la colección a diversos públicos (Figura 2), práctica generosa que es común entre algunos coleccionistas de la época, como Diego Rivera, quien construyó el Anahuacalli para mostrar sus piezas, y el matrimonio de Jacqueline Larralde de Sáenz y Josué Sáenz quienes exhibían en casa sus tesoros estéticos prehispánicos. 
En el caso de Stavenhagen, su hogar también sirvió para entablar relaciones amistosas con Paul Westheim, Fernando Gamboa, Justino Fernández, Diego Rivera, Juan O'Gorman, Miguel Covarrubias, entre otras personalidades del mundo cultural, con quienes discutía y contrastaba sus percepciones sobre el arte prehispánico (Stavenhagen 2011). También realizaba visitas guiadas gratuitas, en las que el discurso estaba completamente en sus manos, lo que, siguiendo a Baudrillard (1969), puede entenderse como una forma de controlar la imagen deseada que las piezas producían acerca de él, esto es, la de un refinado coleccionista de arte prehispánico en una sociedad donde existían varios de ellos. Esta imagen deseada, inseparable de la forma estética y de las narrativas de la colección, le permitió a Stavenhagen unirse a una elite cultural y disfrutar de los privilegios que ésta concedía, como: publicaciones, exposiciones, fiestas, reuniones, viajes y reconocimientos (Figura 3 ).

La forma en la que Stavenhagen representó sus piezas en nuestro espacio es la que O'Gorman (2002) denomina la simple contemplación o simple crítica, que consiste en una relación inmediata y directa con la obra desde el contexto histórico del sujeto observador, quien procura un diálogo con el objeto antiguo para establecer una experiencia estética, pero sin trasladarse al pasado para comprenderlos, sino explicándolos desde el presente con ejemplos y experiencias cotidianas de su contexto.

Kurt Stavenhagen apreciaba la obra prehispánica por su valor estético y soslayaba otros valores relevantes (cfr. Gándara 2014: 35): en primer lugar, se interesó por aquella en la que veía expresiones sentimentales, emociones y escenas de la vida cotidiana. Para el coleccionista:

no hay arte comparable al de México [...]. Es más rico que el arte antiguo de cualquier otro país de América. En el de Mesopotamia, en el que produjeron los etruscos, hititas, sumerios, egipcios, griegos y romanos uno ve

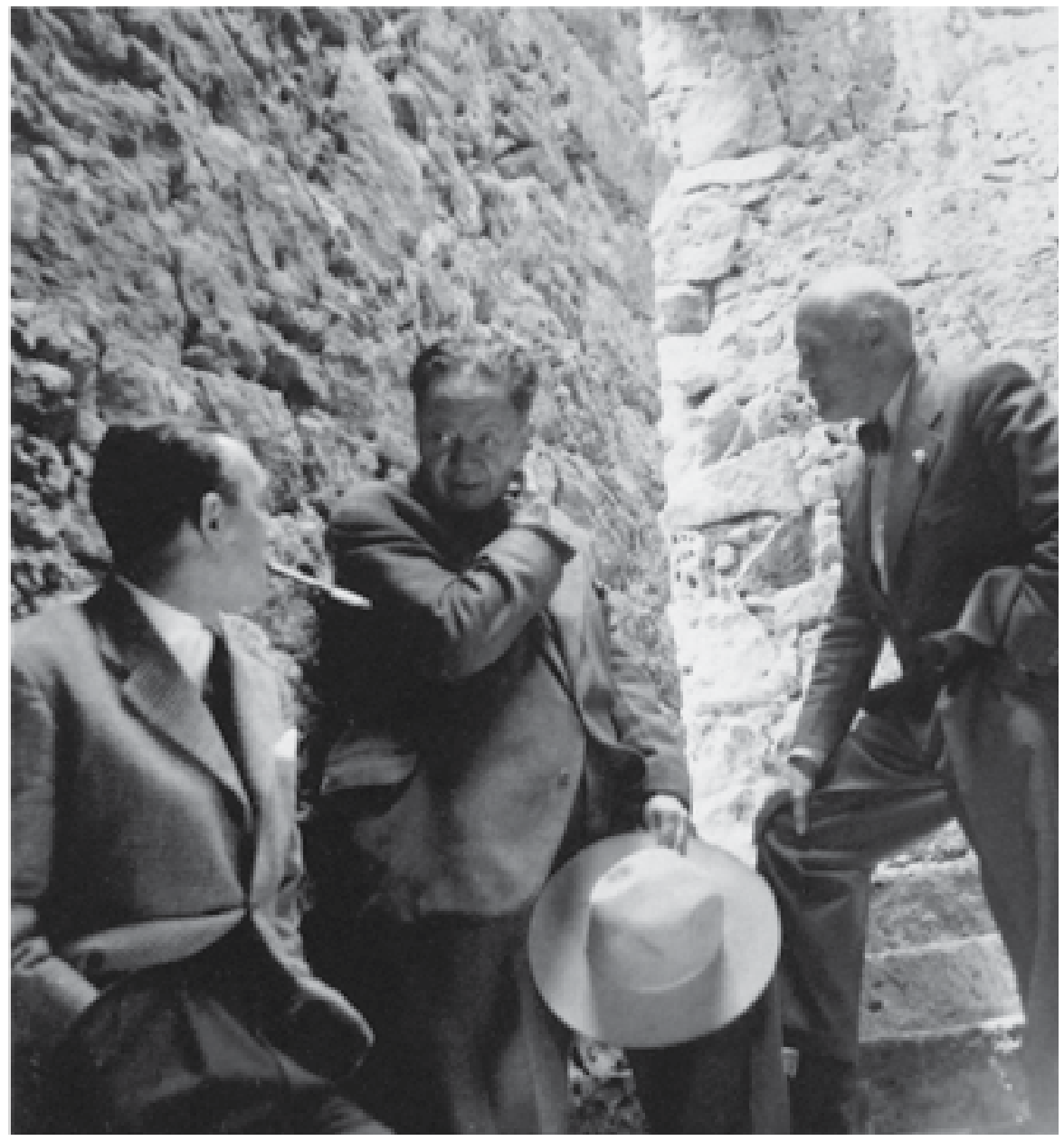

FIGURA 3. Visita a la construcción del Museo Anahuacalli. De izquierda a derecha, los coleccionistas de arte prehispánico Luis Lindau, Diego Rivera y Kurt Stavenhagen (Fotografía: familia Stavenhagen, ca. 1952-1953; cortesía: Archivo privado de la familia Stavenhagen).

rostros idénticos, hermosos pliegues en las ropas, pero no las expresiones que muestran todos los sentimientos que tienen estas piezas" [K. Stavenhagen, citado en Bambi 1982: 2B].

En segundo lugar, están las piezas en las que encontraba similitudes estéticas con el arte moderno de creadores como Picasso, Maillol, Moore y Munch (Figura 4), para "Ilegar a la conclusión de que lo que se hizo en esta parte del mundo hace 2500 años y lo que se produce en este siglo son semejantes" (K. Stavenhagen, citado en Bambi 1982: 2B), es decir, consideraba que el arte moderno tenía más de 2500 años de antigüedad, conclusión que coincidía con la mirada nacionalista posrevolucionaria. Todos estos intereses estéticos o preferencias

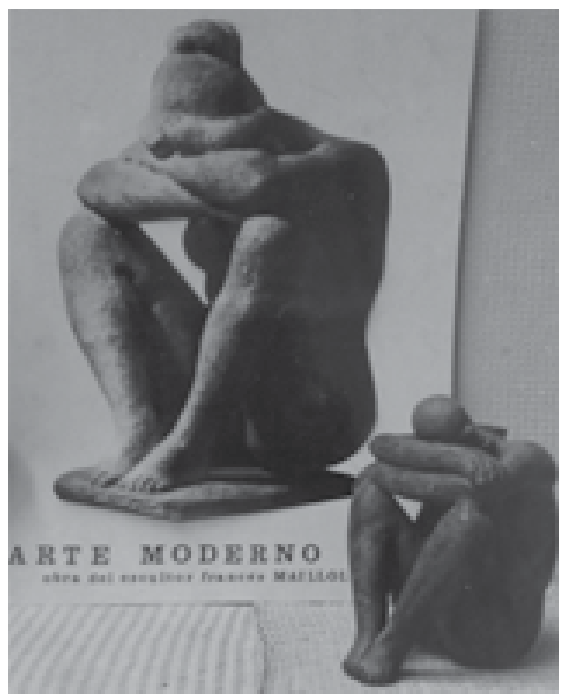

FIGURA 4. Vasija de la colección Stavenhagen comparada con escultura del artista Arístides Maillol (Fotografía: Familia Stavenhagen, s. d.; cortesía: Archivo privado de la familia Stavenhagen). 
tienen reflejo en las temáticas que Stavenhagen creó para seleccionar, ordenar y explicar sus piezas (Figura 5).

La influencia de la mirada nacionalista posrevolucionaria es notable frente a la mirada privada de Stavenhagen, ya que ambas planteaban, como se ha dicho, la revaloración y el redescubrimiento del arte prehispánico (cfr. Westheim, 1955: 22), además de que promovían la idea de la calidad, originalidad y antigüedad del arte mexicano, percepciones reproducidas, primero, por Covarrubias en la exposición Veinte siglos de arte mexicano (1940) y, años más tarde, por Fernando Gamboa en la muestra internacional Obras maestras de arte mexicano, desde los tiempos precolombinos hasta nuestros días (1952-1964), donde la colección Stavenhagen tuvo presencia.

La relevancia de la participación de Stavenhagen en el ámbito del patrimonio cultural no se limita a que

TEMÁTICAS

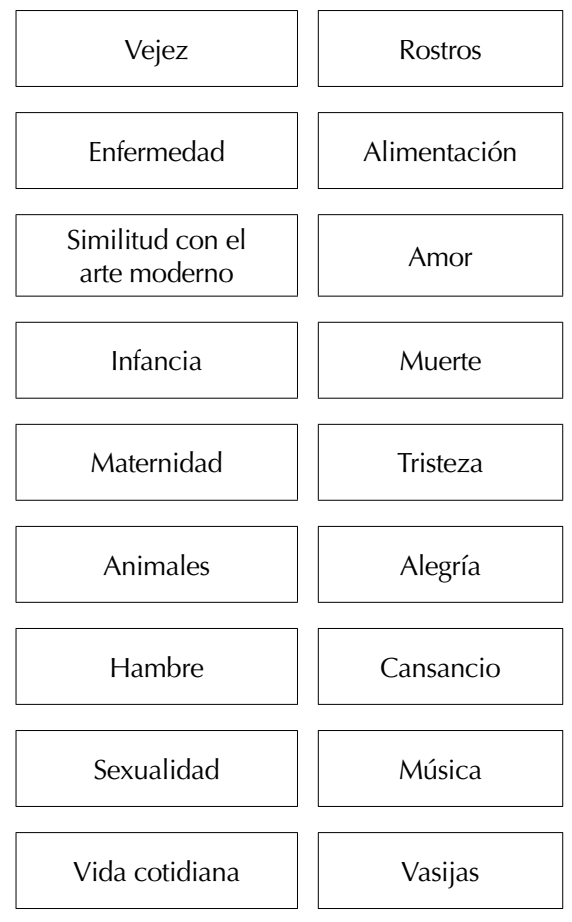

FIGURA 5. Temáticas creadas por Kurt Stavenhagen para seleccionar, organizar y explicar las piezas de la colección. (Gráfico: elaboración propia con base en el testimonio de Sara C Förden [s. f.], frases de Kurt Stavenhagen [K. Stavenhagen, citado en Bambi 1982: 2B] y entrevistas a familiares; 2017).
FIGURA 6. Sala de la exposición Stavenhagen: una pasión por el humanismo prehispánico, instalada en el MCS del 13 de diciembre de 2011 al 31 de octubre de 2017 (Fotografía: Christopher Vargas Reyes, 2016; archivo personal).

reunió cientos de piezas prehispánicas que sirvieron para fundar el MCS, sino que sus esfuerzos por divulgar una nueva mirada estética en el contexto nacional e internacional favorecieron un patrimonio que en México no estaba legitimado como arte, además, su colección es un testimonio de la visión nacionalista posrevolucionaria que ayudó a posicionar la estética prehispánica en la historia universal del arte. Esta mirada configuró colecciones privadas de objetos arqueológicos que se usaron y continúan usándose para crear o ampliar acervos de los museos del país (Figura 6).

Kurt Erwin Stavenhagen falleció en la colonia donde vivió, a los 85 años, el 15 de enero de 1984. Tras ello, la promoción de la colección se detuvo, no se exhibió más y los públicos dejaron de frecuentarla (Bodek 2015). En el 2010, sus familiares preocupados por el futuro del acervo convinieron con la Universidad Nacional Autónoma de México (UNAM) un espacio ex profeso en el CCUT para las piezas, logrando así la materialización del destino manifiesto que el coleccionista deseaba para su acervo: albergarlo y divulgarlo en un museo público.

\section{Agradecimientos}

A Claudia Bodek Stavenhagen (Universidad Nacional Autónoma de México [UNAM]); a Lucía Sánchez de Bustamante (Museo Colección Stavenhagen [MCS]) y a Rodolfo Stavenhagen Gruenbaum (El Colegio de México [Colmex]).

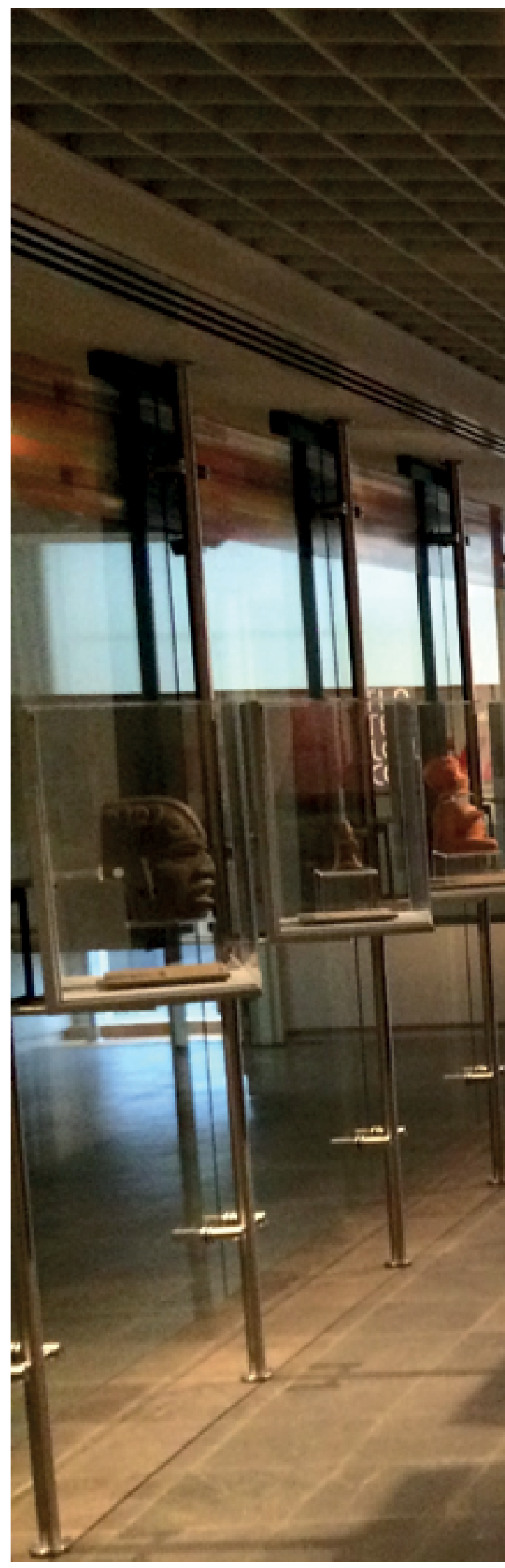




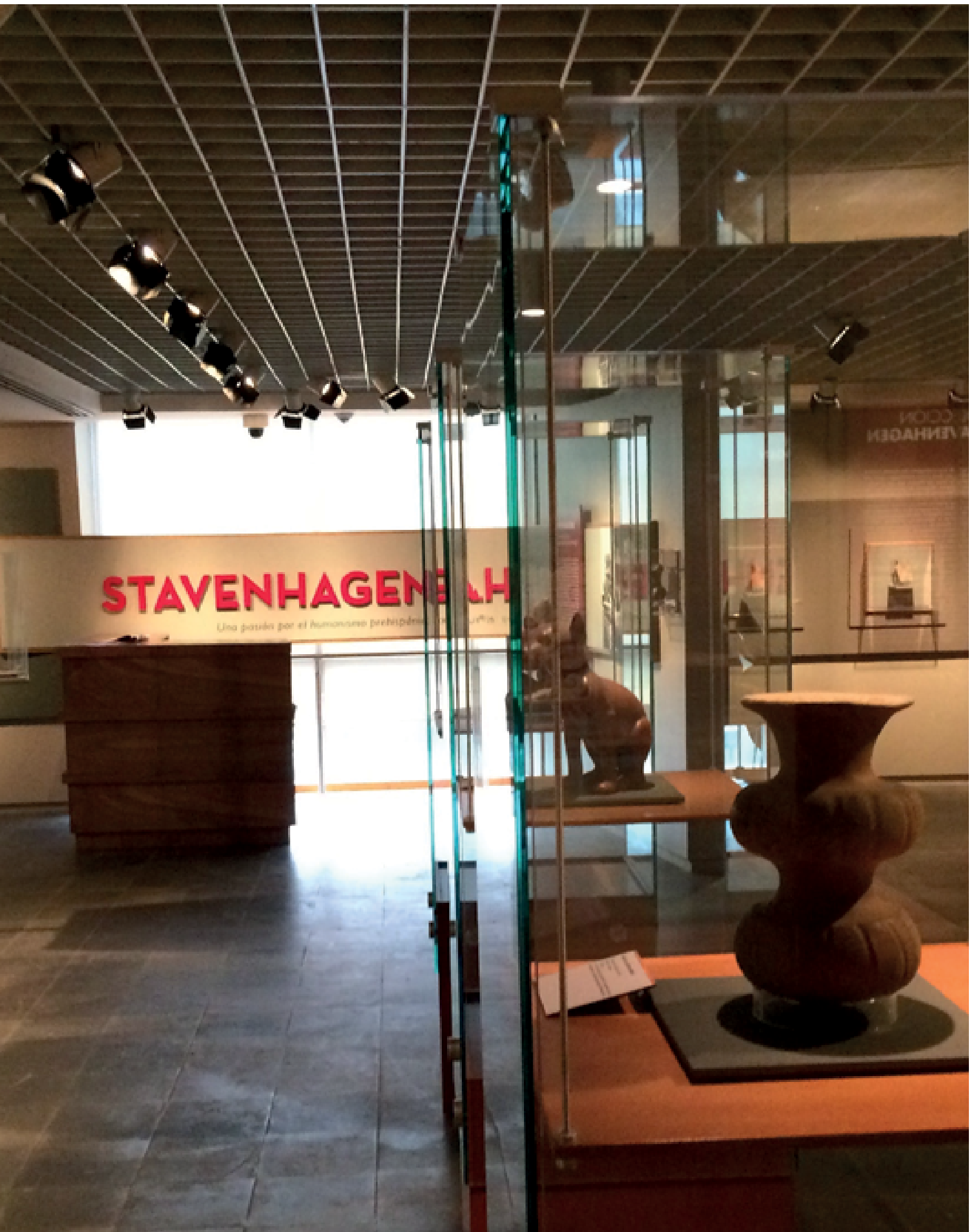




\section{Referencias}

Bambi

1982 "Risas, susto, enojo, alegría, miedo y grito representan las figuras que reunió [Kurt] Stavenhagen", Excélsior, 8 de marzo de 1982, B: 1-2.

Baudrillard, Jean 1969 El sistema de los objetos, trad. de Francisco González Aramburu, México, Siglo XXI Editores.

Benjamin, Walter 2013 "El coleccionista", en Rolf Tiedemann (ed.), Walter Benjamin. Obra de los pasajes [vol. 1], Madrid, Abada Editores, pp. 337-351.

Bernal, Ignacio

1992 Historia de la arqueología en México, $2^{\text {a }}$ ed., México, Porrúa, pp. 119-131.

Bodek Stavenhagen, Claudia

2015 Comunicación personal, entrevista realizada por Christopher Vargas Reyes, 24 de julio, México.

Fernández, Justino

1972 Estética del arte mexicano. Coatlicue. El Retablo de los Reyes. El hombre, México, Instituto de Investigaciones Estéticas, Universidad Nacional Autónoma de México.

Förden, Sara C.

s. f. "A Visit to the Stavenhagen Art Collection", mecanoescrito [reseña], México, Archivo privado de la familia Stavenhagen.

Gándara V., Manuel

2014 "El INAH y la socialización de los valores del patrimonio en sitios arqueológicos: un breve repaso histórico", Gaceta de Museos, 58: 32-37, documento electrónico disponible en [https://revistas.inah.gob.mx/index.php/gacetamuseos/article/ view/559/523], consultado en febrero de 2017.

Guzmán, Eulalia

1933 "Caracteres esenciales del arte prehispánico de México", Revista de la Universidad de México, s/n: 655-663, documento electrónico disponible en [http://www.historicas. unam.mx/publicaciones/publicadigital/libros/lecturas/T3/ LHMT3_073.pdf], consultado el 6 de febrero de 2017.

Morales, Luis Gerardo

1994 Orígenes de la museología mexicana. Fuentes para el estudio histórico del Museo Nacional, 1780-1940, México, Departamento de Historia, Universidad Iberoamericana.

Ocampo, Estela

2011 El fetiche en el museo. Aproximación al arte primitivo, Madrid, Alianza.
O'Gorman, Edmundo

2002 El arte o de la monstruosidad y otros escritos, México, Planeta (Ronda de clásicos mexicanos).

Segob

1940 "Registro de extranjero a Kurt Erwin Stavenhagen", México, mecanoescrito [formulario], Archivo General de la Nación, Secretaría de Gobernación, siglo xx, Dpto. de Migración, Alemanes, caja 25, Sieber-Strall/134037/137/136, Stavenhagen, Kurt Erwin.

Stavenhagen, Rodolfo

2011 “Vivir entonces. Una visión del México antiguo a través del ojo de un apasionado coleccionista de arte", en Carmina Estrada (coord.), Vivir entonces. Creaciones del México antiguo, México, Centro Cultural Universitario Tlatelolco, Universidad Nacional Autónoma de México, pp. 247-280.

Westheim, Paul

1955 "Esencia y espíritu del arte precortesiano", Artes de México, 7: 21-47.

\section{Síntesis curricular del/los autor/es}

\author{
Christopher Vargas Reyes \\ Centro de Investigación y Estudios Superiores en Antropología Social \\ (CIESAS-Sureste), México \\ christopher_vargas_r@encrym.edu.mx
}

Licenciado en historia (Universidad Central de Venezuela [UCV]), cuya tesis, "La expedición libertadora mirandina de 1806. Nuevas interpretaciones", obtuvo la mención honorífica-publicación. Actualmente es candidato a maestro en museología (Escuela Nacional de Conservación, Restauración y Museografía [ENCRyM], Instituto Nacional de Antropología e Historia [INAH], México). De 2002 a 2007 laboró en el Museo de los Niños de Caracas como curador y diseñador de actividades educativas; fue fundador del Museo Barco Leander (Venezuela), donde participó de 2008 a 2012 como coordinador, investigador y curador a través de la Fundación Generalísimo Francisco de Miranda. Entre 2012 y 2014 se desempeñó como coordinador general en el Museo Nacional de Historia (Venezuela). Ha participado en varias curadurías, las últimas en el Museo Nacional de Historia "Castillo de Chapultepec" (México, 2015) y en el Museo Casa Estudio Diego Rivera y Frida Kahlo (México, 2016). Desde 2016 se desempeña como asistente de investigación en el CIESAS Sureste (México).

Postulado/Submitted: 17.03.2018

Aceptado/Accepted: 02.05.2018

Publicado/Published: 15.08.2018 